\title{
Piergiorgio Di Giminiani, Ángel Aedo y Juan Loera Gon- zález. Ecopolíticas globales. Medioambiente, bienestar y poder.
} Santiago, Editorial Hueders. 2016, 316 págs.

\section{MATÍAS CALDERÓN*}

Uno de los desafíos de mayor importancia que tenemos actualmente las/os antropólogas/ os y las/os científicos sociales en general, es plantearnos simultáneamente pequeñas y grandes preguntas de investigación. Pensar y proponerse una sociedad más allá del neoliberalismo, como también, comprender los procesos sociales superando su expresión inmediata y particular, son cuestiones centrales para hacer ciencias sociales con una perspectiva crítica que pretenda, de algún modo y en algún sentido, transformar la sociedad tal cual la hemos conocido. El libro Ecopolíticas globales. Medioambiente, bienestar y poder debe ser valorado, en primer lugar, por ofrecernos y proponernos una diversidad de reflexiones y discusiones que van en esta perspectiva.

El título de la obra ya nos presenta las grandes coordenadas que guían su desarrollo y que están presentes, con distintas aproximaciones y énfasis, en los ocho capítulos de investigación que lo componen (más la introducción). Esto es la imbricación de lo político y lo ecológico en tanto cuestión social contemporánea, pero aprehendida globalmente a partir de una amplia variedad de casos en donde se problematizan los tres ejes enunciados: medioambiente, bienestar y poder.

Para tratar lo anterior los editores congregaron, además de ellos tres, a ocho investigadoras e investigadores (cinco mujeres y tres hombres) afiliados a distintas universidades del mundo, quienes escriben sobre estudios realizados en Perú, Zambia, Chile, Nepal, México, Canadá, Nueva Zelanda y Bolivia. Esta heterogeneidad de casos reunidos es una notable contribución que responde a la perspectiva enunciada en el título, la ecopolítica global. Los casos no deben ser analizados como colecciones aisladas de entes curiosos, por el contrario, son distintas expresiones a lo largo del mundo de las formas en que el poder y las desigualdades se expresan en el marco de relaciones sociedad y naturaleza. Las diferentes bases teóricas que orientan cada uno de los estudios no debe verse como un problema, por el contrario, permiten acercarnos al problema sociedad - naturaleza desde distintos enfoques que lo interrogan en el presente.

No solo se traspasan los nacionalismos metodológicos sino que también los regionales. No se mira a América exclusivamente desde América Latina mediante Perú, Chile, Bolivia y México, sino que también se considera a Canadá en América del Norte, rebasando las criticadas fronteras Norte-Sur pero muchas veces reproducidas cuando se asumen como entes excluyentes para la investigación. Junto con ello, se considera a África (Zambia), Asia (Nepal) y Oceanía (Nueva Zelanda), gran parte del mundo. El mensaje es que, más allá si nos situamos y observamos territorios centrales 
o periféricos del capitalismo global, poder y desigualdad siempre están presentes, de modo heterogéneo, en las configuraciones sociedad naturaleza que emergen en cada espacio.

La propuesta del texto no es la comparación explícita de variables estandarizadas para cada uno de los casos, sino que es más bien una invitación que permite una comparación comprensiva de la ecopolítica siguiendo una hebra global de múltiples formas en que puede expresarse. En este sentido, si seguimos a los editores cuando plantean en la Introducción que la ecopolítica "es un término general que se refiere a la intersección entre política y ecología a distintos niveles tales como la gobernanza internacional, las política públicas y los movimientos sociales [...y que reconoce] el carácter inmanente de la política en las relaciones ecológicas que involucran a los humanos entre sí y también a estos con los no humanos" (pp. 16), el libro nos proporciona ocho entradas a partir de casos concretos de investigación.

Cuando profundizamos por las distintas rutas que se nos ofrecen para adentrarnos en las ecopolíticas globales particulares, observamos diversos procesos concretos, actores, conflictos y escalas, donde se expresa la conexión ecología y política. Por ejemplo, un primer acercamiento interesante está en los capítulos de White (en el área de Chiawa en Zambia), Choque (en el territorio aymara en Chile) y Campbell (en la zona habitada por los tamang en Nepal), donde -entre otras cosas-, se observan distintas dinámicas de conflictos y desigualdades socio-ambientales relacionadas al diseño Estatal de áreas de conservación y protección de la naturaleza, como también, de "desarrollo" económico-social donde el medioambiente, ahora planifi- cado desde afuera al territorio, cumple un rol central. En todos los casos examinados, las poblaciones locales pierden autonomía territorial y en gran medida quedan subordinadas a intereses económicos y políticos externos, viendo afectadas sus prácticas, significaciones y relaciones históricas con el territorio, con los humanos y los no-humanos que ahí habitan. Sin embargo, lo que se muestra no es determinación unidireccional, se da cuenta de distintas estrategias prácticas y discursivas que usan los actores locales para intentar incidir en este nuevo contexto socio-ambiental y, en la medida de sus posibilidades (tanto propias como dadas por el escenario estructural), orientarlo a su favor.

Una segunda aproximación a las políticas de la naturaleza que queremos destacar está en los artículos de Harvey (Perú) y Almanza (norte de México) donde el foco de análisis está en las complejas y a veces contradictorias dinámicas asociadas al desarrollo de una gran infraestructura público-privada. El escrito de Harvey enfatiza la economía política e imaginarios asociados a la planificación y construcción de dos carreteras, como también, las transformaciones y emergencias de relaciones entre humanos y no humanos. No podemos dejar de mencionar el original análisis que realiza, donde además de las ontologías de la naturaleza de las poblaciones locales, aborda la "personeidad" de las carreteras para los ingenieros y la agencia del hormigón. Por su parte, Almanza reflexiona sobre la "criminalidad ambiental" del Estado en relación a la construcción de una presa, un acueducto y el despojo hídrico del río Yaqui. Se plantea la noción de violencia estructural que, por un lado, permite legalmente la depredación ambiental, y por el otro, reprime y sanciona a quienes resisten estas intervenciones. 
La cuestión del conocimiento sobre la naturaleza y la política que implica es la tercera entrada que identificamos, específicamente en los artículos de Müller (región de Saskátchewan en Canadá) y Muru-Lanning (Nueva Zelanda). Müller estudia las relaciones semillas-humanos, concretamente el proceso de privatización de la propiedad intelectual de semillas de canola por parte de grandes empresas y cuáles son los efectos en prácticas y significaciones de agricultores industriales canadienses, generando mecanismos de auto control de los propios agricultores y una serie de discursos/prácticas que ocultan la destrucción y la apropiación de la naturaleza. Mientras que Muru-Lanning trata las relaciones, influencias y articulaciones del saber indígena maorí y el conocimiento científico en torno al agua. Nos permite problematizar que, más allá de las intenciones de los distintos actores, son finalmente las prácticas y conocimientos científicos ortodoxos los que hegemonizan el trabajo conjunto donde el saber indígena se usa en una jerarquía menor a los procedimientos experimentales de las ciencias.

Finalmente, el capítulo de Postero (Bolivia) analiza críticamente el proceso de profundas transformaciones posneoliberales con Evo Morales considerando al Estado, al capital, el medioambiente, la raza, la identidad y el proyecto de "desarrollo", todo ello para comprender la configuración concreta (histórico-geográfica) del capitalismo en Bolivia. Plantea que más allá de los avances realizados y los potenciales futuros sentados por los gobiernos del MAS, el énfasis extractivista mantiene violencias cotidianas y estructurales sobre determinados grupos y territorios, fundamentalmente donde están los recursos que demanda el extractivismo. Ejemplifica con el caso del Territorio Indígena y Parque Nacional Isiboro Secure (TIPNIS) y el conflicto suscitado por la construcción de una carretera transnacional, aborda los diversos -y contradictorios- actores que se posicionaron y articularon en torno a esta disputa que se presentó a diversas escalas y con distintos objetivos.

Ya detallados los principales lineamientos generales de la obra y de los distintos capítulos que lo componen, haré breves comentarios de forma que en nada empañan sus aportes. Considerando el alcance mundial del problema tratado y los casos abordados, hubiese sido adecuado que los editores solicitaran a los autores mapas más detallados de los lugares de estudio para que el lector tuviese claridad de su emplazamiento (más allá de la ubicación del país como se muestra en el mapa global de las páginas 12 y 13). De igual modo, un mayor apoyo de otros soportes como fotografías, habría enriquecido notablemente a los artículos.

Para terminar y retomando lo planteado al comienzo. Este libro estimula a pensar la sociedad actual para construir algo distinto, con mayor bienestar social, justicia medioambiental y distribución de los poderes. Esta obra, en general y en sus capítulos específicos, es aguda en explicitar una mirada crítica, sin embargo, en base a ello no se formulan propuestas de acción o rutas deseadas para impulsar, construir o avanzar en un proceso de transformación social. Esta es una deuda que compartimos gran parte de las ciencias sociales contemporáneas, y especialmente la antropología (me incluyo). La diversidad de miradas llevará necesariamente a diferentes rutas de cambio, lo cual -inevitablemente- será motivo de controversia entre quienes se proponen alguna transformación. Da igual, es un riesgo necesario. Este libro llama a que nos atrevamos a pasar del análisis crítico de la sociedad, a proponer e intentar, con derecho a equivocarse, la sociedad que se quiere. 